\title{
Current and emerging treatments for uterine myoma - an update
}

\author{
This article was published in the following Dove Press journal: \\ International Journal of Women's Health \\ 5 August 20II \\ Number of times this article has been viewed
}

\author{
Nirmala Duhan \\ Pt Bhagwat Dayal Sharma \\ Post Graduate Institute of Medical \\ Sciences, Rohtak, Haryana, India
}

\begin{abstract}
Uterine myomas, the most common benign, solid, pelvic tumors in women, occur in $20 \%-40 \%$ of women in their reproductive years and form the most common indication for hysterectomy. Various factors affect the choice of the best treatment modality for a given patient. Asymptomatic myomas may be managed by reassurance and careful follow up. Medical therapy should be tried as a first line of treatment for symptomatic myomas, while surgical treatment should be reserved only for appropriate indications. Hysterectomy has its place in myoma management in its definitiveness. However, myomectomy, rather than hysterectomy, should be performed when subsequent childbearing is a consideration. Preoperative gonadotropin-releasing hormone analog treatment before myomectomy decreases the size and vascularity of the myoma but may render the capsule more fibrous and difficult to resect. Uterine artery embolization is an effective standard alternative for women with large symptomatic myomas who are poor surgical risks or wish to avoid major surgery. Its effects on future fertility need further evaluation in larger studies. Serial follow-up without surgery for growth and/or development of symptoms is advisable for asymptomatic women, particularly those approaching menopause. The present article is incorporated with multiple clear clinical photographs and simplified elaboration of the available management options for these tumors of uterine smooth muscle to facilitate clear understanding.
\end{abstract}

Keywords: myomectomy, uterine artery embolization, pelvic tumor, hysterectomy, GnRH, leiomyoma

\section{Introduction}

Fibroids are the most common benign uterine tumors, present in $20 \%-25 \%$ of women at reproductive age. Hysterectomy has been the most common treatment modality for symptomatic fibroids in the past. Based on data from 1990 to 1997, the presence of uterine fibroids formed the main indication for hysterectomy in the United States. ${ }^{1}$ Myomectomy, the removal of fibroids surgically without hysterectomy, is the second most common surgical procedure for this condition. ${ }^{2}$ Despite the frequency with which fibroids are diagnosed and treated, there remains considerable uncertainty and controversy among clinicians and women regarding the best way to manage them. ${ }^{3}$

The treatment modalities for uterine myomas may include expectant management, medical therapy, conventional surgical options, and newer and less invasive approaches. Age, parity, childbearing aspirations, extent and severity of symptoms, size, number and location of myomas, associated medical conditions, the risk of malignancy, proximity to menopause, and the desire for uterine preservation are some of the factors affecting the choice of therapeutic approach. ${ }^{4}$ Hence, the treatment should be individualized.
Correspondence: Nirmala Duhan 6/9 J, Medical Campus, PGIMS, Rohtak-I2400I, Haryana, India

Tel $+9 \mid 1262213778$

Mobile +91 9896016348

Email nkadian@gmail.com 
It must be recognized that all conservative management options allow the possibility for new leiomyomas to form, and preexisting small or undetected leiomyomas may exhibit significant growth, necessitating another treatment. The risk of recurrence must be balanced against the potential benefits of uterus sparing procedures, such as lower morbidity and retention of fertility. ${ }^{4}$ If malignancy is suspected, the treatment must be surgical. The present article attempts to review the conventional and newer management options for uterine leiomyomas.

\section{Expectant management}

Asymptomatic women with leiomyoma of the uterus of less than 12 weeks size may be suitable candidates for expectant management, especially those approaching menopause. However, an enlarged uterus may rarely cause significant compression of ureters that could compromise renal function. Piscitelli et al demonstrated ureteral dilatation in 56\% patients with uterine size of 12 weeks or more, but no dilatation in those with uterine size less than 12 weeks. ${ }^{5}$ Women eligible for expectant management may report for follow-up every 3-6 months where a detailed history and clinical examination is carried out to note the uterine size and rate of growth of the tumor.

\section{Medical therapy}

Various medications, both hormonal and nonhormonal, have been tried to control the symptoms produced by fibroids. Most medical therapies cause a significant but temporary reduction in myoma size and improve symptoms in most cases. These interventions may prepare the patient for surgery and in some cases render surgery unnecessary if, in the interim, the patient enters menopause. ${ }^{6}$ For reproductive purposes the effect of medical therapy is less obvious as the myomas tend to regrow on discontinuation of therapy.

\section{Antifibrinolytics}

Tranexamic acid, a synthetic derivative of lysine, exerts its antifibrinolytic effect through a reversible blockade of lysine-binding sites on plasminogen molecules, thus inhibiting the activation of plasminogen to plasmin, which in turn is responsible for fibrin degradation. It has been used as a first-line nonhormonal therapy for heavy bleeding associated with uterine fibroids and dysfunctional uterine bleeding. ${ }^{6}$ It was approved for use for heavy menstrual bleeding by the United States Food and Drug Administration (FDA) in 2009. Prolonged treatment may theoretically increase the risk of deep vein thrombosis; most studies reveal the incidence of thrombosis in women treated with this agent to be similar to that in untreated cases. ${ }^{6}$

\section{Nonsteroidal anti-inflammatory drugs}

Nonsteroidal anti-inflammatory drugs (NSAIDs) are effective in reducing dysmenorrhea and heavy menstrual losses by acting as antagonists of prostaglandins, the agents that stimulate uterine contractility resulting in pain. Aspirin, ibuprofen, and naproxen are effective for dysmenorrhea. However, long-term use of these agents may produce gastric ulcers and gastrointestinal bleeding. Peura suggests that over use of NSAIDs contributes to gastrointestinal adverse effects and anemia by inhibiting the cyclooxygenase- 1 enzyme. ${ }^{7}$

\section{Oral contraceptive pills}

These drugs are often used to control menorrhagia and dysmenorrhea. However, as myomas are estrogen dependent, they may exhibit an increase in size with combined pills. For some women, the benefits of hormonal contraception outweigh the risk of this adverse affect.

\section{Progestogens}

Progestational agents are thought to produce a hypoestrogenic effect by inhibiting gonadotropin secretion and suppressing ovarian function, apart from exerting a direct anti-estrogenic effect at the cellular level. However, recent evidence that the antiprogesterone mifepristone decreases myoma size raises concerns about this mechanism. ${ }^{8}$ Moreover, the beneficial effects of these agents are transient. Asoprisnil, an orally active selective progesterone receptor modulator (SPRM) is being studied for management of symptomatic uterine leiomyomata, as it suppresses both the duration and intensity of menstrual bleeding in a dose-dependent manner. Its use is associated with a statistically significant reduction $(91 \%)$ in frequency and intensity of uterine bleeding in these women. ${ }^{9}$ The exact mechanism of action of this agent is not discernible, but a downregulation of collagen synthesis through upregulation of extracellular matrix metalloproteinase inducer is proposed. ${ }^{10}$ The SPRMs offer the advantages of progesterone antagonism without their adverse effects. ${ }^{6}$ However, a Phase III clinical trial evaluating the long-term (the proposed duration of the study was initially 2 years) safety of this drug in daily oral doses of 10 and $25 \mathrm{mg}$ had to be discontinued prematurely due to changes detected in the endometrial samples. The endometrial changes reverted after discontinuation of the drug. 


\section{Danazol}

Danazol, a synthetic isoxazole derivative chemically related to 17-ethinyl testosterone, creates a high androgen and low estrogen environment resulting in the wasting of endometrium and shrinkage of fibroids. Despite its reported benefits, various undesirable side effects are associated with its use; for example, acne, hirsutism, weight gain, irritability, musculoskeletal pain, hot flushes, and breast atrophy. Danazol has been reported to be an effective therapy to shrink fibroids and control their symptoms. ${ }^{6}$ The anti-estrogenic effect of the agent is the probable mechanism of its efficacy in fibroid management. Patient compliance could be an issue, and a cautious dosing may help overcome the unpleasant adverse effects. However, there is no reliable evidence from randomized controlled trials (RCTs) regarding the benefits and/or harms of use of this drug for treating uterine myomas. ${ }^{11}$

\section{Levonorgestrel intrauterine device}

Use of a levonorgestrel intrauterine device (LNG-IUD) has been shown to be associated with a reduction in the menstrual blood loss in women with uterine myomas. However, reports on its effect on the size of uterine myoma and the uterus as a whole are conflicting. Jindabenjerd et al reported a significant reduction in total myoma volume and average uterine size and a marked reduction in menstrual blood loss, though bleeding disturbances may occur in about $68 \%$ women with its use. ${ }^{12}$ Murat Naki et al reported a menstrual-loss reduction of $60 \%$ and $35 \%$ at the end of 6 months and 2 years, respectively, but did not find any alteration in the myoma and uterine size after treatment with a LNG-IUD. ${ }^{13}$ Women with large myomas may also have more frequent spontaneous expulsion of this device. The device therefore may be more suitable for an undistorted uterine cavity and a uterine size of less than 12 weeks. ${ }^{6}$

\section{Gonadotropin-releasing hormone analogs}

Gonadotropin-releasing hormone analogs (GnRHa) have also been used successfully to achieve hypoestrogenism both as a primary means of conservative therapy for myomas and as an adjunct to myomectomy. Their effects are transient, and the myomas usually return to pretherapy size within a few months of discontinuation. ${ }^{14}$ The reduction in myoma volume by preoperative GnRHa therapy may facilitate a hysteroscopic resection of a submucous myoma with less blood loss, although the tissue planes tend to become more fibrotic and adherent after this therapy. ${ }^{15}$ The amenorrhea induced by preoperative GnRHa therapy may help in building up hemoglobin levels, thus enabling presurgical blood donation for subsequent autotransfusion. Menopausal symptoms, osteoporosis, and pelvic pain are some of the adverse effects of this therapy, and a hormonal add-back, if given, may negate the beneficial effects on myoma size. ${ }^{16}$ Danazol administration has been tried after 6 months of GnRHa therapy in an effort to prolong the therapeutic effects of GnRHa. The bone mineral content that is substantially reduced during GnRHa treatment is reported to significantly improve with danazol, though a rebound of uterine volume due to its antiprogesterone effect is a possibility. ${ }^{17}$ In perimenopausal women, however, a short-term GnRHa therapy may eliminate the need for surgery. Hysterectomy may become technically easier and quicker after pretreatment with GnRHa. With the reduction in uterine size, a greater number of women posted for hysterectomy may be able to undergo a vaginal rather than an abdominal procedure. It also reduces blood loss and rate of vertical abdominal incisions at surgery. Lynesterol does not offer any advantage over GnRHa therapy prior to surgery for uterine myomas. ${ }^{18}$

Several add-back regimes have been tried in women using GnRHa in an effort to reduce the effects of estrogen deficiency. These include tibolone, raloxifene, progestogens alone, estrogens alone, and a combination of estrogens and progestogens. However, a hormonal add-back bears the risk of increase in size and quantity of myomas. Tibolone has a neutral effect on myoma volume, and typical doses of raloxifene have no influence on its growth. Hence, if postmenopausal women with myomas need therapy to control symptoms, tibolone and raloxifene may be more suitable. ${ }^{19}$ Besides, tibolone has also been shown to reverse the deleterious effect on cognition that is caused by leuprolide acetate depot. Its addition improves mood and quality of life in women who receive GnRHa for symptomatic uterine myomas. ${ }^{20}$

\section{Aromatase inhibitors}

Recently, letrozole, a nonsteroidal aromatase inhibitor commonly used in anovulatory infertility in the follicular phase has been suggested to have a potential therapeutic role in treatment of leiomyomas. ${ }^{21}$ Aromatase, a member of the cytochrome p450 superfamily, is a microsomal enyzyme that catalyses conversion of androgens to estrogen. In leiomyoma, both aromatase and 17 $\beta$-hydroxysteroid dehydrogenase type 1 enzymes are overexpressed in comparison with normal myometrium..$^{22}$ Inhibition of aromatase enzyme by letrozole would block this conversion and hence result in an hypoestrogenic environment. As the growth of leiomyoma is positively 
correlated to circulating estrogen levels, the hypoestrogenic milieu would be inhibitory to myoma growth.

Literature on the role of aromatase inhibitors in leiomyoma uterus is limited and comprises mainly a few case reports. Varelas et al reported a $55.7 \%$ reduction in leiomyoma volume and $22.9 \%$ reduction in total uterine volume in their study using anastrazole $1 \mathrm{mg}$ daily for three cycles. ${ }^{22}$ Mohammed et al used letrozole $2.5 \mathrm{mg}$ per day for 12 weeks and found total myoma volume reduction of $45.6 \%$ with no significant change in the hormonal milieu. ${ }^{23}$ Rapid onset of action and avoidance of initial gonadotropin flare with an aromatase inhibitor may be advantageous for management of women who wish to avoid surgical intervention or in whom surgery is contraindicated. Aromatase inhibitors have been found to be as effective as GnRHa, with fewer side effects. However, lack of knowledge of the effects of body mass index on the efficacy of these agents, sparse data on subsequent reproductive outcome, and absence of long-term follow-up data currently restricts the use of these agents to women without infertility.

\section{Mifepristone}

Since exposure to estrogen and progesterone promotes the growth of uterine leiomyomas, treatment with a well studied antiprogestin, mifepristone, has been evaluated. The effect of this agent on follicular development, ovulation, endometerial development, and function is dependent on the dose and timing of exposure; the agent is currently approved for medical abortion. Short-term administration of low doses of 2-5 mg per day to normal cycling women result in anovulation and inhibition of menstruation in over $90 \%$ of menstrual cycles. ${ }^{24}$ The long-term administration of $100 \mathrm{mg} /$ day of mifepristone may induce ovarian acyclicity and relief of pelvic pain in women with endometriosis. ${ }^{25}$ Since endometriosis and fibroids share ovarian steroid dependency, mifepristone may exhibit inhibitory effect on myoma growth. Engman et al treated 30 women with leiomyoma uterus with $50 \mathrm{mg}$ mifepristone for 3 months prior to surgery and found a $28 \%$ reduction in the leiomyoma volume compared with $6 \%$ for the placebo group. ${ }^{26}$ Mifepristone may represent a viable alternative to $\mathrm{GnRHa}$ for use in the preoperative application. Moreover, if the safety of long-term, low-dose mifepristone is established, perimenopausal women with large, symptomatic fibroids may be able to take this medication until menopause, when the myoma typically regresses. Consequently, it would yield major savings in cost and morbidity in view of the large number of hysterectomies done for leiomyomata in perimenopausal women. In addition, younger women with large leiomyomata who wish to retain their fertility may also benefit from chronic low-dose mifepristone, until the time that they wish to conceive.

\section{CDB-2914}

CDB-2914, an antiprogestin, given in daily doses of 10-20 mg for three cycles, has been reported to reduce fibroid size by $36 \%$, compared with a $6 \%$ increase with placebo. ${ }^{27}$ Of the 18 women included in the only available study evaluating the role of this drug on myoma volume, patients received a 10 or $20 \mathrm{mg}$ dose of CDB-2914 daily or an inactive placebo. Only one woman (out of a total of six) in the study experienced menstrual bleeding during treatment with CDB-2914. Low estrogen levels were evident in the CDB-2914 group and it may be safer than other medical therapies for myoma due to the drug's relatively specific antiprogesterone effect. ${ }^{27}$

\section{Magnetic resonance-guided focused ultrasound surgery}

In October 2004, the FDA approved magnetic resonance imaging (MRI)-guided focused ultrasound treatment of uterine fibroids in humans, which is being sold as ExAblate in the United States. The rise in temperature of the tissue receiving the high intensity focused ultrasound and the resultant protein denaturation and irreversible cell damage form the basis of this treatment modality. ${ }^{28}$ The method uses multiple exposures of high intensity focused ultrasound energy on the target fibroid to raise the tissue temperature to levels high enough to destroy it. The MRI not only allows a three-dimensional precise view of the target tissue, but also provides quantitative, real-time thermal images of the treated area. Most myomas appear as sharply marginated areas of low to intermediate signal intensity while one-third may have inhomogenous areas of high signal intensity (resulting from hemorrhage, degeneration, edema, or high cellular content) on T2-weighted images. Symptomatic women who are otherwise free of any contraindication to MRI and desiring a noninvasive therapeutic outpatient option for myoma are suitable candidates for this modality. A reduction of up to $98 \%$ in myoma volume and symptoms has been reported with this noninvasive treatment for symptomatic myomas. ${ }^{29}$ However, the efficacy of magnetic resonance-guided focused ultrasound surgery (MRgFUS) correlates with signal intensity of T2-weighted magnetic resonance images. Those with low signal intensity on pretreatment images are more likely to shrink than those with high signal intensity. ${ }^{30}$ The larger the nonperfused volume immediately after treatment, the greater the volume reduction and symptom relief. Thus, Type 1(low intensity) and 2 (intermediate intensity) fibroids are suitable 
for this treatment, while Type 3 (high intensity) myomas are not. ${ }^{31}$

Women having a myoma volume of more than $500 \mathrm{~cm}^{3}$ may be pretreated with a GnRHa for 3 months in an attempt to reduce the size to improve the efficacy of thermal ablation. ${ }^{32}$ It has been suggested that the use of GnRHa potentiates the thermal effects of MRgFUS, particularly in women with uterine diameter of $10 \mathrm{~cm}$ or more. ${ }^{33}$ Small myoma size, intramural location, fewer number, and $\mathrm{T}_{2}$ hypodensity are important predictors of treatment success. ${ }^{34}$ Symptomatic improvement lasts for over 2 years, and 16\%-20\% women may need additional therapy. ${ }^{35}$ Although there is paucity of large RCTs between MRgFUS and uterine artery embolization (UAE), initial reports suggest MRgFUS is comparable in efficacy, safety, and cost effectiveness to UAE. ${ }^{36}$

\section{Uterine artery embolization}

This procedure, first described for management of myomas in 1995, attempts to limit growth by limiting the blood supply. Polyvinyl alcohol particles of $500 \mu \mathrm{m}$ size are passed through a fluoroscopically guided transarterial catheter inserted in the common femoral artery to selectively occlude the arteries supplying the myoma. This short interventional radiologic procedure requires a short hospital stay and is recommended for large symptomatic myomas in women who do not wish or are poor candidates for major surgery. Goodwin et al reported the long-term outcomes from the FIBROID (Fibroid Registry for Outcomes Data) registry based on a 3-year study of 2112 patients who underwent uterine artery embolization for symptomatic leiomyomas. ${ }^{37}$ The procedure was found to be associated with improvement in quality of life and a subsequent need for hysterectomy, myomectomy, or repeat uterine artery embolization in $9.79 \%, 2.82 \%$, and $1.83 \%$ patients, respectively. Persistent ischemic pain, postembolization fever, severe postembolization syndrome, pyometra, sepsis, hysterectomy, and even deaths have been reported after the procedure. ${ }^{38}$ Ovarian failure may ensue in $1 \%-2 \%$ patients, though successful pregnancies too have been reported after embolization. $^{39}$

A retrospective cohort study showed that UAE has much fewer serious adverse effects than hysterectomy (odds ratio 0.25 ) and similar rates of satisfaction. ${ }^{40}$ In this study, $86 \%$ women treated with UAE would recommend the procedure to a friend in comparison to $70 \%$ of those who underwent hysterectomy. A review of two RCTs comparing UAE with abdominal hysterectomy in 234 women found that UAE reduced fibroid-related menstrual blood loss by $85 \%$ and the dominant fibroid volume by $30 \%-46 \%$. It also significantly reduced the length of hospital stay at the time of the procedure but was associated with more minor complications, unscheduled hospital visits, and higher readmission rates than hysterectomy. ${ }^{41}$ It may be advisable to withhold GnRHa therapy if UAE is planned, as the GnRHa-related constriction of the uterine vessels may cause technical difficulty at UAE. The procedure should preferably be done after 12 weeks of stoppage of GnRHa therapy.

\section{Surgical management}

Careful observation is suitable for most myomas, as most of them produce no symptoms, are confined to the pelvis, and are rarely malignant. ${ }^{42}$ Surgical options may be considered in cases of abnormal uterine bleeding that is unresponsive to conservative management, a high degree of suspicion of pelvic malignancy, growth of myoma after menopause, distortion of endometrial cavity or tubal obstruction in infertile women and in those with recurrent pregnancy losses, pain, or pressure symptoms interfering with quality of life, and anemia secondary to chronic uterine blood loss.

\section{Abdominal myomectomy}

Myomectomy has been the procedure of choice for symptomatic myomas in women desiring retention of uterus and often for a solitary pedunculated myoma. However, the number of tumors is no limitation for this procedure. Since submucous myomas have been implicated in the etiology of infertility and recurrent pregnancy loss, myomectomy is recommended by some before gonadotrophin stimulation for in vitro fertilization and also in women with large myomas that may interfere with oocyte retrieval. ${ }^{4}$ Nevertheless, this continues to be a controversial area, and the removal of an otherwise asymptomatic large myoma which does not distort the endometrial cavity may not be a reasonable proposition in these cases. The procedure may be considered in patients with large myomas, especially those with a distorted endometrial cavity and in those with unexplained in vitro fertilization failures. ${ }^{17}$

A thorough preoperative evaluation is advisable prior to myomectomy. Women with menstrual irregularities and those with risk of endometrial pathology require endometrial histologic evaluation before myomectomy, particularly if aged more than 35 years. ${ }^{4}$ Hysteroscopy, if available, may be useful at the time of endometrial sampling in diagnosing intrauterine pathology like polyps, foreign bodies, or forgotten intrauterine devices. In our opinion, definitive surgery should be deferred for 4-6 weeks after hysteroscopy so as to minimize the chances of disseminated infection. 
Optimization of hematological status of the patient prior to surgery is of paramount importance. The anemic woman should be pretreated with GnRHa or progestational agents to produce amenorrhea. Stored autologous or donated blood should be arranged for surgery.

The procedure can be carried out by laparoscopy or laparotomy. A meta-analysis of six RCTs and 576 patients suggests that laparoscopic myomectomy is associated with less hemoglobin drop, reduced operative blood loss, more patients fully recuperated at day 15 , diminished operative pain, and fewer overall complications, but longer operation time ${ }^{43}$ The study concluded that if performed by suitably specialized surgeons in selected patients, laparoscopic myomectomy is a better choice than open surgery. However, the quality of uterine repair would influence the risk of uterine rupture during a subsequent pregnancy event. Hemorrhage and adhesion formation continue to be other areas of concern after myomectomy. The therapeutic choice between a myomectomy, hysterectomy, or other surgical options should be based on age and the desire for fertility preservation.

The blood loss at surgery correlates with uterine size, weight of myomas removed, and the operating time. Various pharmacologic vasoconstricting agents and mechanical vascular occlusion techniques have been tried to minimize surgical blood loss. A meta-analysis of 10 RCTs and 531 participants analyzed the various hemostatic measures used - intramyometrial vasopressin and analogs, intravenous oxytocin, vaginal misoprostol, peri-cervical tourniquet, chemical dissection with sodium-2-mercaptoethane sulfonate (mesna), intramyometrial bupivacaine plus epinephrine, tranexamic acid, and enucleation of myoma by morcellation while it is attached to the uterus. ${ }^{44}$ All these measures except oxytocin and enucleation by morcellation were found to result in reduced bleeding at myomectomy, while oxytocin and morcellation were not found to affect the operative blood loss.

The isthmic myomas may be a class apart among the myomas as far as growth dynamics are concerned. They are reported to be subjected to uterine peristaltic waves in opposite directions during different phases of the menstrual cycle, thus resulting in a tangential growth. ${ }^{45}$ This may pose difficulty in apprehending the extent and correct anatomic relations at the time of surgery. Figure 1 is a clinical intraoperative photograph taken during myomectomy of an anterior isthmic fibroid and a normal-sized body of the uterus. The patient was a 21-year-old nulliparous woman presenting with a lump in the abdomen and infertility.

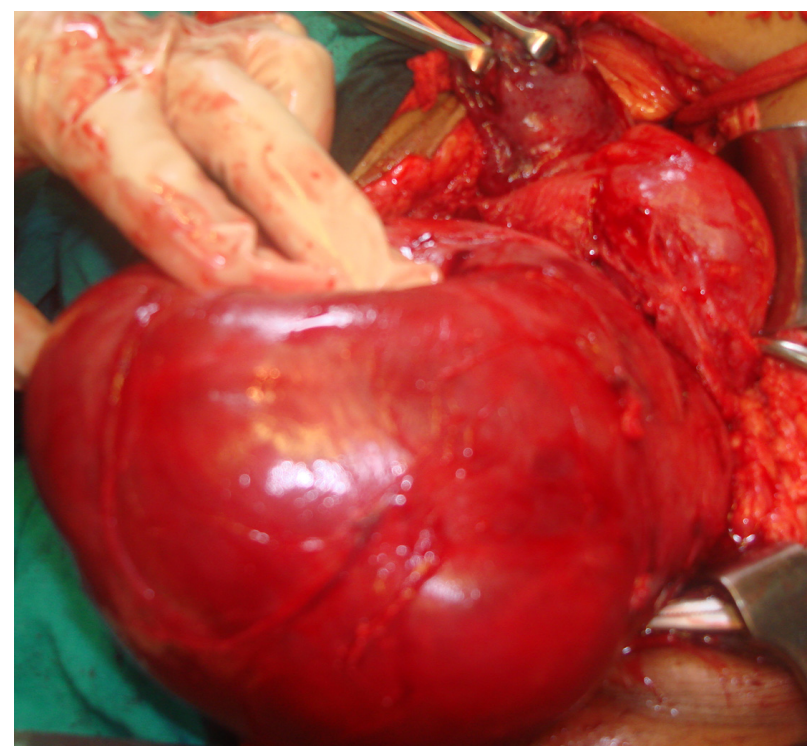

Figure I A clinical intraoperative photograph taken during myomectomy of an anterior isthmic fibroid and a normal-sized body of the uterus.

Adequate exposure, hemostasis, careful handling of reproductive tissues, and adhesion prevention are some of the general principles of abdominal myomectomy. The operative morbidity associated with this procedure has not been shown to be any higher than that of hysterectomy. ${ }^{46}$ When extensive dissection of the myometrium has been necessary during myomectomy, irrespective of the actual opening of the endometrial cavity, a subsequent cesarean delivery is advisable.

\section{Hysteroscopic myomectomy}

This procedure is indicated for abnormal bleeding, history of pregnancy loss, infertility, and pain, while suspicion of endometrial malignancy, inability to distend the cavity or circumnavigate the lesion, and tumor extension deep into the myometrium are the chief contraindications. Around $20 \%$ of women will need additional therapy within 10 years of this procedure, mainly due to incomplete removal or new myoma growth. ${ }^{4}$ The European Society of Hysteroscopy classifies submucous myomas according to the extent of myometrial invasion into four categories to help the hysteroscopist plan the surgical approach. ${ }^{47}$ Category T:O includes all pedunculated submucus myomas. Submucus myomas extending less than $50 \%$ into the myometrium are classified as T:I, while those with greater than $50 \%$ penetration are classified as T:II. Category T:O and T:I can be removed hysteroscopically by a surgeon with modest previous experience, while Category T:II myomas should be resected abdominally, and hysteroscopic resection should be reserved for highly skilled hysteroscopic surgeons. 
Reduction in myoma volume by preoperative GnRHa therapy may facilitate a hysteroscopic resection of a submucus myoma with less blood loss, although the tissue planes tend to become more fibrotic, adherent, and less clear after this treatment. ${ }^{15}$ Figure 2 is a hysteroscopic view of a submucus myoma arising from the uterine fundus.

\section{Vaginal myomectomy}

Large myomas arising from the uterine body may fill the vagina and result in intermenstrual bleeding, unhealthy discharge, or urinary retention. Most of these can be enucleated per vaginum and the stalk ligated. Rarely, they may form the etiological basis of a uterine inversion, particularly the large ones arising from the fundus. Figure 3 is an intraoperative clinical photograph of ipsilateral inversion of the right side of the fundus consequent upon a large stalked myoma reaching up to the introitus and filling the vagina.

\section{Laparoscopic/robotically assisted laparoscopic myomectomy}

Superficial subserous or pedunculated myomas are best suited for laparoscopic or robotically assisted laparoscopic removal. Their removal is effected by either morcellation, utilization of a colpotomy incision, or myolysis. Laparoscopic myomectomy in infertile women with intramural myomas offers comparable results to laparotomy, and the pregnancy rates tend to be affected by other associated infertility factors. ${ }^{48}$ Uterine rupture during pregnancy after laparoscopic myomectomy has been attributed to inadequate reconstruction of myometrium during surgery. All women wishing to undergo myomectomy

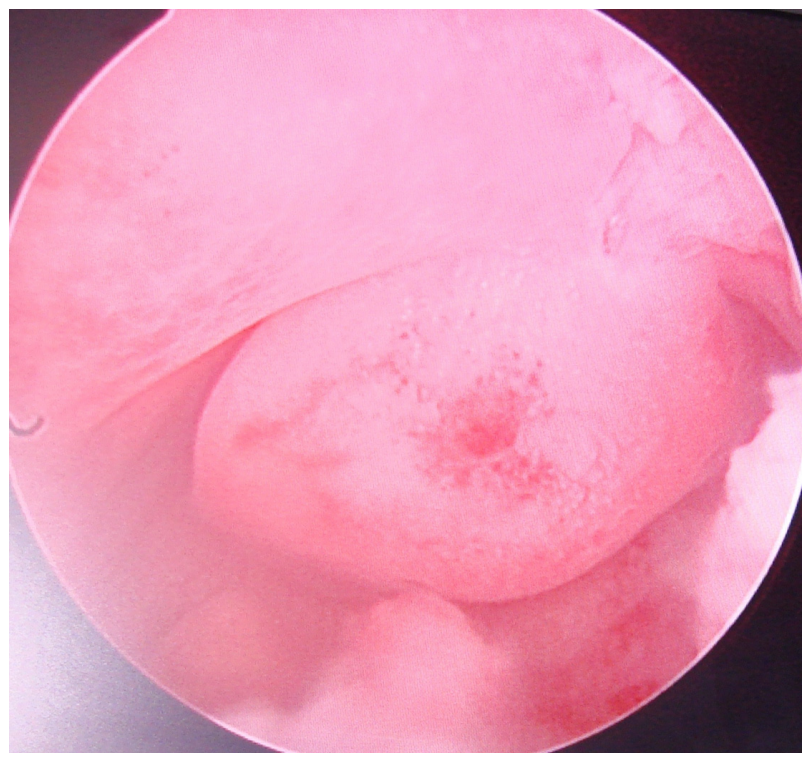

Figure 2 A pedunculated fundal submucus myoma at hysteroscopy.

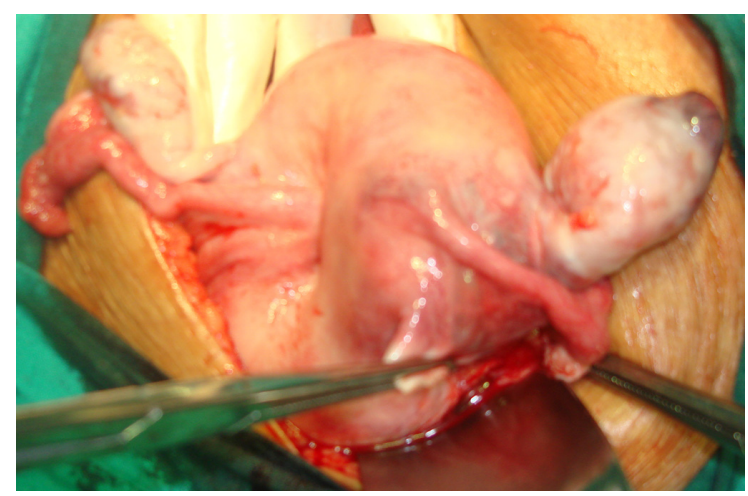

Figure 3 Partial (right-sided) inversion of uterine fundus caused by a large stalked myoma arising from the fundus.

should be willing for a hysterectomy, if need be. The finding of a diffuse leiomyomatosis in a woman posted for myomectomy is not uncommon. For those who desire conception, a delay of 4-6 months before attempting pregnancy is recommended after myomectomy to allow for myometrial healing.

\section{Hysterectomy}

Hysterectomy is the most common major gynecological surgical procedure performed in women, and $33.5 \%$ of these are done for myomas. ${ }^{4}$ Depending on the size, number, and location of the tumors, the skill of the surgeon and the availability of instruments, the open technique, laparoscopy, and vaginal route are the other ports of access to the myoma-bearing uterus. Hysterectomy has been the surgical procedure of choice for myomas when childbearing considerations have been fulfilled or when there is reasonable likelihood of malignancy. Figure 4 is a clinical photograph of leiomyosarcoma arising

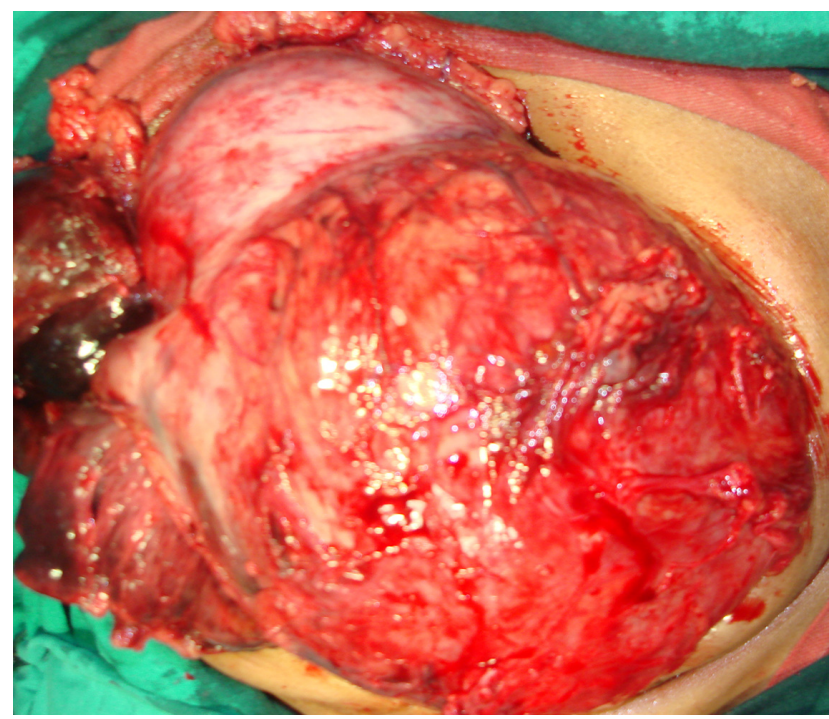

Figure 4 A clinical photograph of leiomyosarcoma arising in a leiomyomatous uterus as seen at hysterectomy. 
in a leiomyomatous uterus of a 36-year-old parous woman presenting with menometrorrhagia. Hysterectomy is associated with a high degree of patient satisfaction, eliminates the need for progestational agents and enables the woman to take unopposed estrogen therapy without many concerns. Recently, nondescent vaginal hysterectomy of a myomatous uterus has generated appreciable interest. However, the procedure may be ideally suited only up to 12 weeks uterine size. Procedures like morcellation, bisection, coring, or wedge resection of the uterus may be successful in skilled hands if the uterine size exceeds 12 weeks. Besides the myoma/uterine size, presence of adhesions, previous pelvic/lower abdominal surgeries, and nonavailability of surgeon skilled in the procedure are other contraindications for nondescent vaginal hysterectomy. Figure 5 shows a nondescent vaginal hysterectomy of a myomatous uterus in progress. Adhesions and anatomic distortions of the uterus pose an increased risk of damage to the urinary and intestinal tract at hysterectomy. Hysterectomy for broad ligament myoma has been reported to carry a ureteric injury risk of $0.4 / 1000 .{ }^{49}$ False broad ligament myomas tend to push the ureter laterally and posteriorly, in contrast to true broad ligament fibroids where the ureter is medial to the myoma. Figures 6 and 7 are intraoperative photographs of true and false broad ligament myomas taken at hysterectomy. Knowledge of the precise location and origin of the myoma as well as skill and experience of the surgeon is of immense importance in order to avoid inadvertent injuries to the urinary tract. Similarly, large cervical myomas pose difficulties as well as increase the risk of urinary tract injury during application of clamps on the Macenrodt's and uterosacral ligaments. Figure 8 shows a normal sized uterine body sitting atop a large

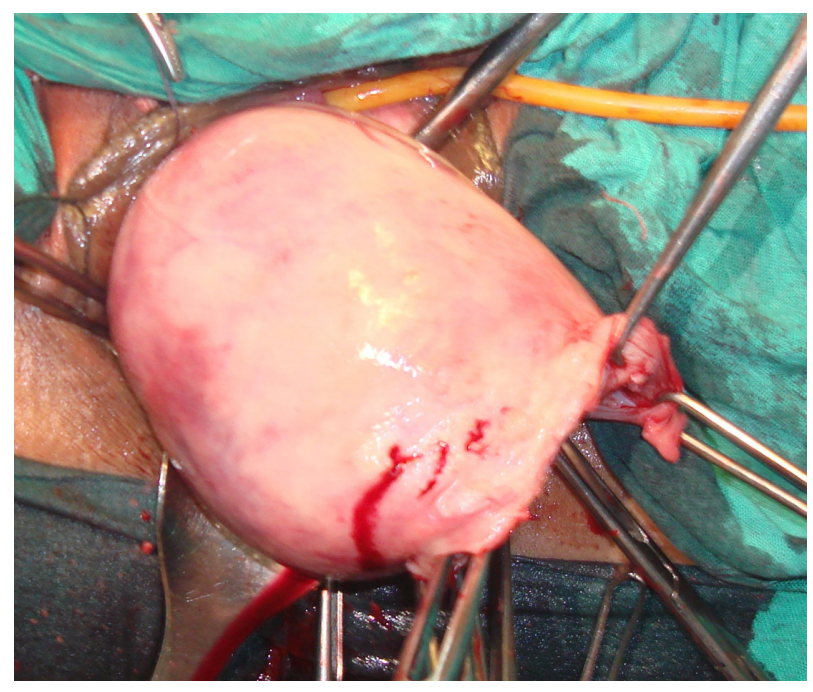

Figure 5 A nondescent vaginal hysterectomy of a myomatous uterus in progress.

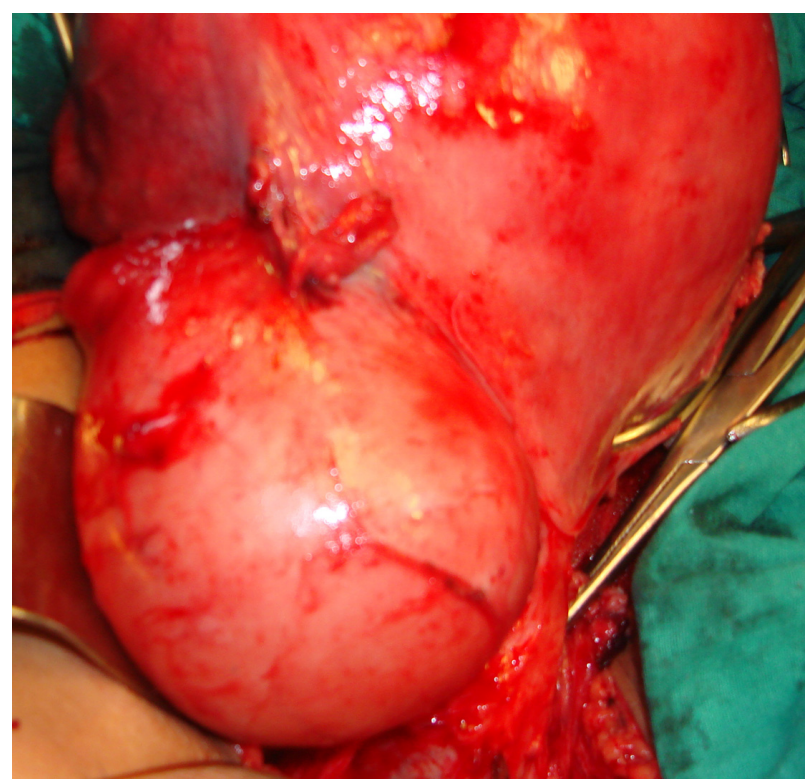

Figure $6 \mathrm{~A}$ false broad ligament myoma as seen at laparotomy.

posterior cervical myoma after hysterectomy. Conservation of cervix at hysterectomy has been proposed to reduce the risk of subsequent vaginal vault prolapse and to maintain good sexual function. ${ }^{50} \mathrm{~A}$ supracervical hysterectomy is also associated with a decreased risk of urinary tract injury and requires less operating time. However, the need for cervical screening for cancer of the cervix in women undergoing supracervical hysterectomy is maintained. Around 61.4\% women over 45 years of age undergoing hysterectomy for

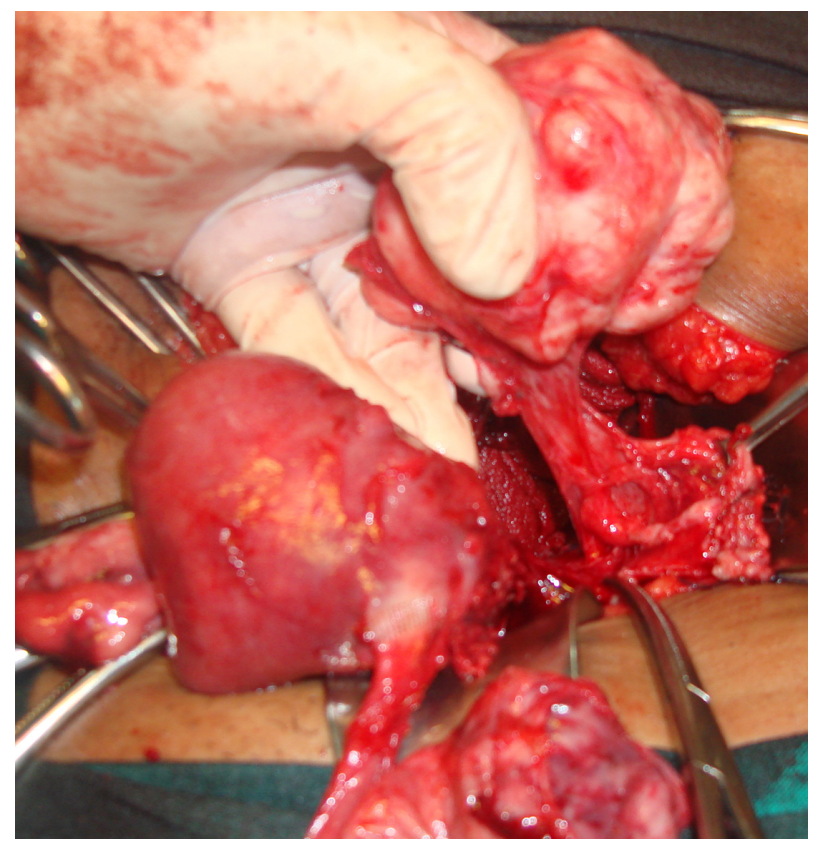

Figure 7 Intraoperative clinical photograph of enucleation of a true broad ligament myoma. 


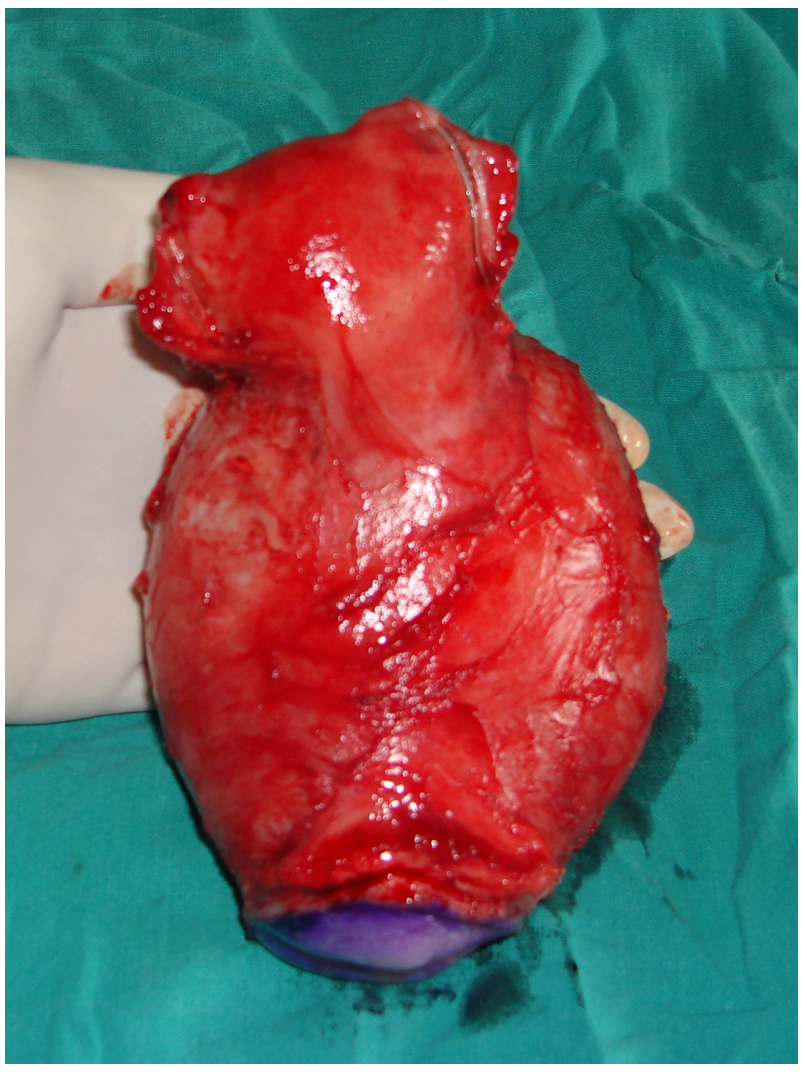

Figure 8 Clinical photograph showing uterine body perched atop a cervical myoma at hysterectomy.

myoma also undergo concomitant bilateral ophorectomy. ${ }^{51}$ The opinion regarding preservation of apparently healthy ovaries continues to be divided. At least for women less than 45 years of age, the ovaries should be spared.

\section{Myolysis}

Various forms of myolysis - bipolar, cryo, radiofrequency, laparoscopic, and MRI-guided laser, have been tried as conservative alternatives to myomectomy in women wishing uterine preservation. ${ }^{52,53}$ Carbon dioxide laser has been used to directly vaporize small myomas at laparotomy, while medium and large myomas are excised. Improved hemostasis and greater precision at removal appear to be the chief advantage, but the technique has not been tested in a larger series of patients. Some submucous myomas have been successfully treated by Nd:YAG (neodymium-doped yttrium aluminium garnet) laser, which devascularizes the myoma; however, incomplete removal may be an issue of concern at times.

\section{Uterine artery ligation}

This procedure attempts to limit the blood supply to the uterus by a vaginal or laparoscopic ligation of the uterine artery. The procedure shares its underlying principle with UAE but is relatively easier to perform. Akinola et al found the uterine artery ligation to be as effective as UAE, while Hald et al found it to be less effective in direct comparison to UAE. ${ }^{54,55}$ The procedure has also been tried in association with myomectomy and is reportedly associated with less introperative blood loss compared with myomectomy carried out without it. ${ }^{56}$ The procedure may reduce postpartum blood loss and minimize the need for future surgery in pregnant women with uterine myomas, who are undergoing cesarean section. ${ }^{57}$ Subsequent fertility does not appear to be adversely affected by the procedure. A combination of uterine artery occlusion (UAO) and simultaneous blockage of anastomosis between uterine and ovarian vessels may be better than $\mathrm{UAO}$ alone in terms of long-term symptom control and reintervention rates. ${ }^{58}$ However, women undergoing simultaneous utero-ovarian anastomosis vessel occlusion are at greater risk of a significant increase in serum folliclestimulating hormone levels at the first month after surgery, thus reflecting a diminished ovarian function. ${ }^{59}$

\section{Conclusion}

Asymptomatic myomas can be managed by reassurance and careful follow up. Medical therapy should be tried as a first-line of treatment for symptomatic myomas, while surgical treatment should be reserved only for appropriate indications. Hysterectomy has its place in myoma management in its definitiveness. However, myomectomy, rather than hysterectomy, should be performed when subsequent childbearing is a consideration. Preoperative GnRH-analog treatment before myomectomy decreases the size and vascularity of the myoma but may render the capsule more fibrous and difficult to resect. Uterine artery embolization is an effective standard alternative for women with large symptomatic myomas who are poor surgical risks or wish to avoid major surgery. Its effects on future fertility need further evaluation in larger studies. Serial follow-up without surgery for growth and/or development of symptoms is advisable for asymptomatic women, particularly those approaching menopause. MRgFUS represents an alternative modality of conservative treatment of uterine myomas and is comparable to UAE for efficacy, safety, and cost.

\section{Disclosure}

The author reports no conflicts of interest in this work.

\section{References}

1. Farquhar CM, Steiner CA. Hysterectomy rates in the United States 1990-1997. Obstet Gynecol. 2002;99:229-234.

2. Guarnaccia MM, Rein MS. Traditional surgical approaches to uterine fibroids: abdominal myomectomy and hysterectomy. Clin Obstet Gynecol. 2001;44(2);385-400. 
3. Myers ER, Barber MW, Couchman GM, et al. Management of uterine fibroids. Evidence Report/Technology Assessment No. 34. (Prepared by the Duke Evidence-based Practice Center under Contract No. 290-97-0014.) AHRQ Publication 01-E052. Rockville, MD: Agency for Healthcare Research and Quality; 2001.

4. Duhan N, Sirohriwal D. Uterine myomas revisited. Eur J Obstet Gynecol Reprod Biol. 2010;152:119-125.

5. Piscitelli JT, Simel DL, Addison WA. Who should have intravenous pyelogram before hysterectomy for benign disease? Obstet Gynecol. 1987;69:541-545.

6. American College of Obstetricians and Gynecologists. ACOG Practice Bulletin. Alternatives to hysterectomy in the management of leiomyomas. Obstet Gynecol. 2008;112(2 Pt 1):387-400.

7. Peura DA. Gastrointestinal safety and tolerability of nonselective nonsteroidal anti-inflammatory agents and cyclooxygenase-2-selective inhibitors. Cleve Clin J Med. 2002;69:S131-S139.

8. Eisinger SH, Meldrum S, Fiscella K, Le Roux HD, Guzick DS. Low dose mifepristone for uterine leiomyomata. Obstet Gynecol. 2003;101: 243-250.

9. Wilkens J, Chwalisz K, Han C, et al. Effects of the selective progesterone receptor modulator asoprisnil on uterine artery blood flow, ovarian activity, and clinical symptoms in patients with uterine leiomyomata scheduled for hysterectomy. J Clin Endocrinol Metab. 2008;93(12): 4664-4671.

10. Morikawa A, Ohara N, Xu Q, et al. Selective progesterone receptor modulator asoprisnil down-regulates collagen synthesis in cultured human uterine leiomyoma cells through up-regulating extracellular matrix metalloproteinase inducer. Hum Reprod. 2008;23(4): 944-951.

11. Ke LQ, Yang K, Li C-M, Li J. Danazol for uterine fibroids. Cochrane Database Syst Rev. 2009;(3):CD007692.

12. Jindabanjerd K, Taneepanichskul S. The use of levonorgestrel-IUD in the treatment of uterine myoma in Thai women. $J$ Med Assoc Thai. 2006;89(4):5147-5151.

13. Murat Naki M, Tekcan C, Ozcan N, Cebi M. Levonorgestrel-releasing intrauterine device insertion ameliorates leiomyoma-dependent menorrhagia among women of reproductive age without a significant regression in the uterine and leiomyoma volumes. Fertil Steril. 2010;94(1): 371-374.

14. Golan A. GnRH analogues in the treatment of uterine fibroids. Hum Reprod. 1996;11:33-41.

15. DeFalco M, Staibano S, Mascolo M, et al. Leiomyoma pseudocapsule after presurgical treatment with gonadotropin releasing hormone agonists: relationship between clinical features and immunohistochemical changes. Eur J Obstet Gynecol Reprod Biol. 2009;144:44-47.

16. Crosignani PG, Vercellini P, Meschia M, Oldani S, Bramante T. GnRH agonists before surgery for uterine biomyomas: a review. J Reprod Med. 1996;41:415-421.

17. De Leo V, Morgante G, Lanzetta D, D’Antona D, Bertieri RS. Danazol administration after gonadotropin-releasing hormone analogue reduces rebound of uterine myomas. Hum Reprod. 1997:12(2):357-360.

18. Lethaby A, Vollenhoven B, Sowter MC. Preoperative GnRH analogue therapy before hysterectomy or myomectomy for uterine fibroids. Cochrane Database Syst Rev. 2001(2):CD000547.

19. Carranza LS. Relation between hormonal therapy and tibolone with SERMs in postmenopausal women's myomas growth. Ginecol Obstet Mex. 2008;76(10):610-614.

20. Palomba S, Orio F Jr, Falbo A, Oppedisano R, Tolini A, Zullo F. Tibolone reverses the cognitive effects caused by leuprolide acetate administration, improving mood and quality of life in patients with symptomatic uterine leiomyomas. Fertil Steril. 2008;90(1): $165-173$.

21. Karaer O, Oru A, Koyuncu FM. Aromatase inhibitors: possible future applications. Acta Obstet Gynecol Scand. 2004;83(8):699-706.

22. Varelas FK, Papanicolaou AN, Vatvatsi N, Makidos GA, Vlassis GD. The effect of anastrazole on symptomatic uterine leiomyomata. Obstet Gynecol. 2007;110(3):643-649.
23. Mohammed EA, Mina A, Saeed A, et al. A randomized controlled clinical trial comparing the effects of aromatase inhibitor (letrozole) and gonadotropin-releasing hormone agonist (triptorelin) on uterine leiomyoma volume and hormonal status. Fertil Steril. 2010;74(1): 192-198.

24. Baird DT, Brown A, Critchley HO, Williams AR, LinS, Cheng L. Effect of long-term treatment with low-dose mifepristone on the endometrium. Hum Reprod. 2003;18:61-68.

25. Kettel LM, Murphy AA, Morales AJ, Ulmann A, Baulieu EE, Yen SS. Treatment of endometriosis with the antiprogesterone mifepristone (RU486). Fertil Steril. 1996;65(1):23-28.

26. Engman M, Granberg S, Williams ARW, Meng CX, Lalit Kumar PGL, Gemzell-Danielsson K. Mifepristone for treatment of uterine leiomyoma. A prospective randomized placebo controlled trial. Hum Reprod. 2009;24(8):1870-1879.

27. Levens ED, Potlog-Nahari C, Armstrong AY, et al. CDB-2914 for uterine leiomyomata treatment: a randomized controlled trial. Obstet Gynecol. 2008;111(5):1129-1136.

28. Terzic M. Focused ultrasound for treatment of uterine myoma: from experimental model to clinical practice. Srp Arh Celok Lek. 2008;136: 193-195.

29. De Melo FC, Dicoyannis L, Moll A, Tovar-Moll F. Reduction by $98 \%$ in uterine myoma volume associated with significant symptom relief after peripheral treatment with magnetic resonance imaging-guided focused ultrasound surgery. J Minim Invasive Gynecol. 2009:16:501-503.

30. Lenard ZM, McDannold NJ, Fennessy FM, et al. Uterine leiomyomas: MR imaging-guided focused ultrasound surgery-imaging predictors of success. Radiologia. 2008;249(1):187-194.

31. Funaki K, Fukunishi H, Funaki T, Sawada K, Kaji V, Maruo T. Magnetic resonance-guided focused ultrasound surgery for uterine fibroids: relationship between the therapeutic effects and signal intensity of preexisting T2-weighted magnetic resonance images. Am J Obstet Gynecol. 2007;196(2):184.e1-e6.

32. Smart OC, Hindley JT, Regan L, Gedroyc WG. Gonadotrophin releasing hormone and magnetic resonance guided ultrasound surgery for uterine leiomyomata. Obstet Gynecol. 2006;108(1):49-54.

33. Smart OC, Hindley JT, Regan L, Gedroye WM. Magnetic resonance guided focused ultrasound surgery of uterine fibroids- the tissue effects of GnRH agonist pretreatment. Eur J Radiol. 2006;59(2):163-167.

34. Yoon SW, Lee C, Cha SH, et al. Patient selection guidelines in MR-guided focused ultrasound surgery of uterine fibroids: a pictorial guide to relevant findings in screening pelvic MRI. Eur Radiol. 2008;18(12):2997-3006.

35. Stewart EA, Robinovici J, Tempany CMC, et al. Clinical outcomes of focused ultrasound surgery for the treatment of uterine fibroids. Fertil Steril. 2006;85(1):22-29.

36. Zowall H, Cairns JA, Brewer C, Lamping DL, Gedroyc WMW, Regan L. Cost effectiveness of mangnetic resonance-guided focused ultrasound surgery for treatment of uterine fibroids. BJOG. 2008;115(5):653-662.

37. Goodwin SC, Spies JB, Worthington-Kirsch R, et al. Uterine artery embolization for treatment of leiomyomata: long-term outcomes from the FIBROID Registry. Obstet Gynecol. 2008;111(1):22-33.

38. Hurst BS, Stackhouse DJ, Mathews ML, Marshburn PB. Uterine artery embolization for symptomatic uterine myomas. Fertil Steril. 2000:74:855-869.

39. Ravina JH, Vigneron NC, Aymard A, Le Dref O, Merland J. Pregnancy after embolization of uterine myoma: report of 12 cases. Fertil Steril. 2000;73:1241-1243.

40. Hirst A, Dutton S, Glu O, et al. A multi-centre retrospective cohort study comparing the efficacy, safety and cost effectiveness of hysterectomy and uterine artery embolization for the treatment of symptomatic uterine fibroids. The HOPEFUL study. Health Technol Assess. 2008;12(5):1-248, iii.

41. Gupta JK, Sinha A, Lumsden MA, Hickey M. Uterine artery embilization for symptomatic uterine fibroids. Cochrane Database Syst Rev. 2006(1):CD005073. 
42. Lefebvre G, Vilos G, Allairi C, et al. The management of uterine leiomyomas. J Obstet Gynecol. 2003;25:395-418.

43. Jin $\mathrm{C}, \mathrm{Hu} \mathrm{Y}$, Chen XC, Zheng FY, Lin F, Zhou K, et al. Laparoscopic versus open myomectomy - a meta-analysis of randomized controlled trials. Eur J Obstet Gynecol Reprod Biol. 2009;145:14-21.

44. Kongnyuy FJ, Wiysonge CS. Interventions to reduce hemorrhage during myomectomy for fibroids. Cochrane Database Syst Rev. 2009;(3):CD005355.

45. Duhan N, Rajotia N, Duhan H, Sangwan N, Gulati N, Sirohiwal D. Isthmic uterine fibroids: the dynamics of growth. Arch Gynecol Obstet. 2009;280:309-312.

46. Sawin SW, Pilevsky ND, Berlin JA, Barnhart NT. Comparability of perioperative morbidity between abdominal myomectomy and hysterectomy for women with uterine leiomyomas. Am J Obstet Gynecol. 2000;183:1448-1455.

47. Cohen IS, Valle RF. Role of vaginal sonography and hysterosonography in endoscopic treatment of uterine myomas. Fertil Steril. 2000;73:197-204.

48. Morita M, Asakawa Y. Reproductive outcome after laparoscopic myomectomy for intramural myomas in infertile women with or without associated infertility factors. Reprod Med Biol. 2008;5: $31-35$.

49. Harkki SP, Sjoberg j, Tiitinen A. Urinary tract injuries after hysterectomy. Obstet Gynecol. 1998:92:113-118.

50. Thakar R, Ayers S, Clarkson P, Stanton S, Manyonda L. Outcomes after total versus subtotal abdominal hysterectomy. $N$ Engl $J$ Med. 2002;347:1318-1325.

51. Wilcox LS, Koonin LM, Pokras R, Strauss LT, Xia Z, Peterson HB. Hysterectomy in the United States, 1988-1990. Obstet Gynecol. 1994:83:549-555.
52. Goldfarb HA. Myoma coagulation (myolysis). Obstet Gynecol Clin North Am. 2000:27:421-430.

53. Cowan BD, Sewell PE, Howard JC, Arriola RM, Robinette LG. Interventional magnetic resonance imaging cryotherapy of uterine fibroid tumors: preliminary observation. Am J Obstet Gynecol. 2002; 186:1183-1187.

54. Akinola OI, Fabamwo AO, Ottun AT, Akinniyi OA. Uterine artery ligation for management of uterine fibroids. Int J Gynecol Obstet. 2005;91(2):137-140.

55. Hald K, Noreng HJR, Istre O, Klow NE. Uterine artery embolization versus laparoscopic occlusion of uterine arteries for leiomyomas: long term results of a randomized comparative trial. J Vasc Intern Radiol. 2009;20(10):1303-1310.

56. Liu L, Li Y, Xu H, Chen Y, Zhang G, Liang Z. Laparoscopic transient uterine artery occlusion and myomectomy for symptomatic uterine myoma. Fertil Steril. 2011;95(1):254-258.

57. Liu WM, Wang PH, Tang WL, Wang IT, Tzeng CR. Uterine artery ligation for treatment of pregnant women with uterine leiomyomas who are undergoing cesarean section. Fertil Steril. 2006;86(2):423-428.

58. Lee WL, Liu WM, Fuh JL, Tsai YC, Shih CC, Wang PH. Use of uterine vessel occlusion in the management of uterine myomas: two different approaches. Fertil Steril. 2010;94(5):1875-1881.

59. Lee WL, Liu WM, Fuh JL, Tsai YC, Shih CC, Wang PH. Basal FSH level changes after different types of uterine vessel occlusion in the management of uterine fibroids. Fertil Steril. 2010;94(6):2286-2290.
International Journal of Women's Health

\section{Publish your work in this journal}

The International Journal of Women's Health is an international, peerreviewed open-access journal publishing original research, reports, reviews and commentaries on all aspects of women's healthcare including gynecology, obstetrics, and breast cancer. Subject areas include: Chronic conditions (migraine headaches, arthritis, osteoporosis);

\section{Dovepress}

Endocrine and autoimmune syndromes; Sexual and reproductive health; Psychological and psychosocial conditions. The manuscript management system is completely online and includes a very quick and fair peer-review system. Visit http://www.dovepress.com/ testimonials.php to read real quotes from published authors. 